\title{
Comparative potency approach based on H2AX assay for estimating the genotoxicity of polycyclic aromatic hydrocarbons
}

\author{
M. Audebert a,b,*, F. Zeman ${ }^{\text {c }}$, R. Beaudoin ${ }^{\mathrm{c}}$, A. Péry ${ }^{\mathrm{c}}$, J.-P. Cravedi ${ }^{\mathrm{a}, \mathrm{b}}$ \\ a INRA UMR1331; TOXALIM (Research Center in Food Toxicology); 180 chemin de Tournefeuille, F-31027 Toulouse, France \\ ${ }^{\mathrm{b}}$ Université de Toulouse, INP, ENVT, EIP, UPS, UMR1331, Toxalim, F-31076 Toulouse, France \\ " Unité "Modèles pour l'écotoxicologie et la toxicologie" (METO), INERIS, BP2, F-60550 Verneuil-en-Halatte, France
}

\section{A R T I C L E I N F O}

\section{Article history:}

Received 21 September 2011

Revised 18 January 2012

Accepted 21 January 2012

Available online 30 January 2012

\section{Keywords:}

Polycyclic aromatic hydrocarbons

Modelization

Toxic Equivalent Factor

Genotoxicity

H2AX

HepG2

LS-174T

\begin{abstract}
A B S T R A C T
Polycyclic Aromatic Hydrocarbons (PAHs) constitute a family of over one hundred compounds and can generally be found in complex mixtures. PAHs metabolites cause DNA damage which can lead to the development of carcinogenesis. Toxicity assessment of PAH complex mixtures is currently expressed in terms of toxic equivalents, based on Toxicity Equivalent Factors (TEFs). However, the definition of new TEFs for a large number of PAH could overcome some limitations of the current method and improve cancer risk assessment. The current investigation aimed at deriving the relative potency factors of PAHs, based on their genotoxic effect measured in vitro and analyzed with mathematical models. For this purpose, we used a new genotoxic assay ( $\gamma \mathrm{H} 2 \mathrm{AX}$ ) with two human cell lines (HepG2 and LS-174T) to analyze the genotoxic properties of 13 selected PAHs at low doses after 24 h treatment. The dose-response for genotoxic effects was modeled with a Hill model; equivalency between PAHs at low dose was assessed by applying constraints to the model parameters. In the two cell lines tested, we observed a clear dose-response for genotoxic effects for 11 tested compounds. LS-174T was on average ten times more sensitive than HepG2 towards PAHs regarding genotoxicity. We developed new TEFs, which we named Genotoxic Equivalent Factor (GEF). Calculated GEF for the tested PAHs were generally higher than the TEF usually used. Our study proposed a new in vitro based method for the establishment of relevant TEFs for PAHs to improve cancer risk assessment.
\end{abstract}

(c) 2012 Elsevier Inc. All rights reserved.

\section{Introduction}

Most polycyclic aromatic hydrocarbons (PAHs) are formed during incomplete combustion of organic compounds. Industrial activities, waste incineration or domestic activities such as eating at home using wood or fossil fuel producing large quantities of PAHs. Humans can be exposed to PAHs through different routes. For the general population, the major routes of exposure are from food and inhaled air, while in smokers, the contributions from smoking and food may be of a similar magnitude. The contaminants are generally complex mixtures of PAHs rather than single compounds. PAHs are of concern because most of them have shown carcinogenicity in experimental animals and genotoxicity in vitro and in vivo (Bostrom et al., 2002; IARC, 2010; US-EPA, 2010).

PAHs genotoxicity is mainly due to metabolic pathways which result in the formation of highly reactive intermediates (Xue and Warshawsky, 2005). One of the most important biotransformation processes leads to the formation of stable pro-mutagenic DNA adducts. The principal catalysts of this activation of PAHs are cytochromes P450 (CYP) family 1

\footnotetext{
* Corresponding author at: INRA-UMR1331, Toxalim, 180 chemin de Tournefeuille BP 9317331027 Toulouse Cedex 3, France. Fax: + 33561285244.

E-mail address: marc.audebert@toulouse.inra.fr (M. Audebert).
}

(CYP1A1, CYP1A2 and CYP1B1) and microsomal epoxide hydrolase to yield reactive diol epoxides.

Fifteen out of the 33 PAHs considered by Scientific Committee on Food (European Commission, 2002), show clear evidence of mutagenicity and/or genotoxicity in somatic cells in vivo and carcinogenic effects. Although only benzo[a]pyrene $(\mathrm{BaP})$ is considered carcinogenic to humans (Group 1, IARC 2010), all these compounds are regarded as potentially genotoxic and carcinogenic to humans. BaP is often used as a reference in studies on the toxicity of PAH mixtures based on relative potency factors (RPFs). Many attempts have been made to anticipate the toxic effect of PAH mixtures by deriving RPFs, also termed Toxic Equivalency Factors (TEFs), on the basis of available in vitro or in vivo toxicity data. The TEF approach has been extensively used for hazard assessment of different classes of chemical mixtures such as polychlorinated biphenyls (PCBs) and dioxins (Van den Berg et al., 1998). This approach relies upon two key assumptions related to the application of a dose-additivity model: (1) a common toxicological mode of action for all components of the mixture, (2) the absence of interactions among components of the mixture at typical human exposure levels (Safe, 1998; European Commission, 2002; US-EPA, 2010).

The gastro-intestinal tract is the first target tissue for food contaminants like PAHs. In a previous study, we examined three different cell 
lines for their ability to biotransform PAHs (Audebert et al., 2010). We concluded that liver cells (HepG2) and colon cells (Caco-2) were able to metabolize PAHs. Nevertheless, the Caco-2 cell line was not suited to our genotoxic assay (Audebert et al., 2010). This new genotoxic assay was based on the detection of the phosphorylation of the histone $\mathrm{H} 2 \mathrm{AX}$ (named $\gamma \mathrm{H} 2 \mathrm{AX}$ ) that reflects a global genotoxic insult resulting from diverse type of DNA damage, notably DNA adducts and oxidative lesions (Zhou et al., 2006; Watters et al., 2009; Audebert et al., 2011; Graillot et al., 2012).

Sixteen priority PAH were recommended by the US Environmental Protection Agency (US-EPA, 2010) for the analysis of environmental samples, namely naphthalene, acenaphthylene, acenaphthene, fluorene, phenanthrene, anthracene, fluoranthene (Fla), pyrene (Pyr), benz $[a]$ anthracene $(\mathrm{BaA})$, chrysene $(\mathrm{Chr})$, benzo[b]fluoranthene $(\mathrm{BbF})$, benzo[ $k]$ fluoranthene $(\mathrm{BkF}), \mathrm{BaP}$, indeno[1,2,3-cd]pyrene (IP), dibenz $[a, h]$ anthracene (DBahA), benzo[ghi]perylene (BghiP). In addition to the 15 PAHs classified by SCF as priority food contaminants (European Commission, 2002), the joint FAO/WHO Expert Committee on Food Additives (FAO/WHO, 2005) also identified benzo[c]fluorene $(\mathrm{BcF})$ as a compound to be included in the list. Accordingly, in a recent risk assessment report on PAHs in food, the European Food Safety Authority (EFSA, 2008) took into account these 16 PAHs. EFSA concluded that BaP, BaA $\mathrm{BbF}, \mathrm{BkF}$, BghiP, Chr, DBahA and IP were currently the only possible indicators of the carcinogenic potency of PAHs in food.

In the present study, we analyzed the genotoxic potential of these 8 PAHs, to which we added BcF, due to the recommendations from JECFA (FAO/WHO, 2005), EFSA (EFSA, 2008) and US-EPA (US-EPA, 2010), dibenzo[a,l]pyrene (DBalP) because it was found to have a much stronger carcinogenic activity than BaP (Wynder and Hoffmann, 1961), Pyr and Fla as negative controls (Durant et al., 1996), and 7,12Dimethyl-benz[a]anthracene (DMBA) because this model compound is widely used as tumor initiator. First, the genotoxicity of the 13 selected compounds were tested in human hepatoma cell line HepG2 and human epithelial colorectal adenocarcinoma cells LS-174T, with a new sensitive genotoxic assay based on H2AX phosphorylation detection. In a second step, the dose-response relationship for genotoxic effects of each compound in the two cell lines was modeled and analyzed with a Hill model. This model is one of the most often applied to dose-response relationships (Walker and Yang, 2005). We used a new method to establish TEFs for PAHs using the complete doseresponse at low dose for each PAH. The new values of TEFs that we propose for the 13 PAHs studied would likely improve the relevance of cancer risk assessment for humans exposed to PAHs. Because our TEF values are based on H2AX genotoxic data, we termed them Genotoxic Equivalent Factor (GEF).

\section{Materials and methods}

Caution: PAHs are hazardous compounds and should be handled with care in accordance with the NIH guidelines for the laboratory use of chemical carcinogens.

\section{Chemicals and reagents}

Benz $[a]$ anthracene, benzo[ $b]$ fluoranthene, benzo[c]fluorene, benzo [k]fluoranthene, benzo[ghi]perylene, chrysene, fluoranthene, pyrene, dibenz $[a, h]$ anthracene, 7,12-Dimethyl-benz[a]anthracene and benzo [a]pyrene (with chemical purity $>97 \%$ ) were obtained from SigmaAldrich (Saint Quentin Fallavier, France) and dissolved in dimethyl sulfoxide (DMSO) obtained from Sigma-Aldrich. Dibenzo[a,l]pyrene and indeno[1,2,3-cd]pyrene were obtained from Chiron (Trondheim,
Norway). Concentration of stock solutions was $5 \mathrm{mM}$. Cells were exposed to $0.2 \%(\mathrm{v} / \mathrm{v})$ DMSO in culture medium.

\section{Cell lines and cultures}

HepG2 human hepatoblastoma cells (ATCC No. HB-8065) and LS174T human epithelial colorectal adenocarcinoma cells (ATCC No. CL-188) were cultured in $\alpha \mathrm{MEM}, 10 \%$ fetal calf serum $\mathrm{v} / \mathrm{v}$, penicillin $\left(100 \mathrm{U} \mathrm{ml}^{-1}\right)$, streptomycin $\left(100 \mu \mathrm{g} \mathrm{ml}^{-1}\right)$, in a $5 \% \mathrm{CO}_{2}$ atmosphere at $37^{\circ} \mathrm{C}$.

\section{In Cell Western (ICW) assay}

The In Cell Western technique was performed essentially as previously described (Audebert et al., 2010; Audebert et al., 2011; Graillot et al., 2012). Briefly, cells were dispensed in 96-well cell culture plate $\left(40 \times 10^{3}\right.$ cells $/ 200 \mu \mathrm{L} /$ well $)$ and were treated in duplicate, $16 \mathrm{~h}$ later, with compounds or vehicle (DMSO) in serum free medium. After $24 \mathrm{~h}$ treatment, cells were washed in PBS and directly fixed in the plate with $4 \%$ paraformaldehyde (Electron Microscopy Science) in PBS for $20 \mathrm{~min}$ at room temperature (RT), then washed using PBS for $5 \mathrm{~min}$. Paraformaldehyde was neutralized with $20 \mathrm{mM} \mathrm{NH}_{4} \mathrm{Cl}$ for 2 min and then washed with PBS for 5 min. Cells were permeabilized with $0.2 \%$ Triton X-100 in PBS for 5 min and washed with PBS, $2 \%$ fetal calf serum, $0.2 \%$ Triton X-100 (PST buffer). Cells were blocked with MAXblock Blocking medium (Active Motif, Belgium) supplemented with phosphatase inhibitor PHOSTOP (Roche) for $60 \mathrm{~min}$ at RT, followed by $2 \mathrm{~h}$ incubation with rabbit monoclonal anti $\gamma \mathrm{H} 2 \mathrm{AX}$ in PST buffer. The antibody used in our study is a monoclonal antibody from rabbit against anti-phospho-H2AX (Clone 20E3), from Cell Signalling Technology (Danvers, MA, USA). After three 5 min washes in PST, secondary detection was carried out using an infrared fluorescent dye conjugated to goat antibody with an absorption peak at $770 \mathrm{~nm}$ (CF770, Biotium) in PST buffer. For DNA labeling, TO-PRO-3 iodide (Molecular Probes) in PST was used in conjugation with the secondary antibody. After a $1 \mathrm{~h}$ incubation and three 5 min washes in PST, DNA and $\gamma \mathrm{H} 2 \mathrm{AX}$ were simultaneously visualized using an Odyssey Infrared Imaging Scanner (Li-CorScienceTec, Les Ulis, France) with the 700-nm fluorophore (red color) and the $800-\mathrm{nm}$ fluorophore (green dye), respectively. Raw absorbance data was averaged for the duplicate, corrected for background; the relative fluorescence units from the scanning allowed a quantitative analysis. The ICW technique allows the determination of cytotoxicity and genotoxicity in a single experiment (O'Brien et al., 2006; Audebert et al., 2010; Audebert et al., 2011). For determination of genotoxicity, relative fluorescent units for $\gamma \mathrm{H} 2 \mathrm{AX}$ per cell (as determined by $\gamma \mathrm{H} 2 \mathrm{AX}$ divided by DNA content) were divided by the respective controls (vehicle only), in order to determine the change in phosphorylation of $\mathrm{H} 2 \mathrm{AX}$ levels relative to control. For determination of cytotoxicity, DNA content recorded in the different experiments was compared to DNA content in control cells. Statistical analysis was performed to seek for significant effects of PAH treatment. All experiments were carried out at least four times independently.

\section{Data analysis}

Statistical analyses were performed using Student's t-test (onetailed test). Statistical analysis was performed using the R Software. Error bars represent SEM (the standard error of the mean). Statistically significant increase in $\mathrm{H} 2 \mathrm{AX}$ phosphorylation compared with DMSO control; *, $p<0.05 ;{ }^{* *}, p<0.01$.

\section{Modeling PAHs genotoxicity}

Formation of DNA adducts by genotoxic carcinogens and subsequent repair are expected to be proportional to dose as long as the 
rates of the enzymatic and non-enzymatic activation and inactivation reactions are all proportional to the substrate concentration. Deviations from linearity are expected in situations of induced and saturated kinetics (Lutz, 1991). The nature of such a dose-response and in particular, its shape, can be obtained by mathematical modeling of observed effects and subsequent interpretation of the model parameters about shape at "low doses". The 4-parameter sigmoidal Hill model is one of the models most often used to model dose-response (Walker and Yang, 2005).

The Hill function we used has the general form:

$E=1+\left(E_{\max }-1\right) \frac{c^{n}}{c^{n}+c_{50}^{n}}$

where the baseline activity when the dose is equal to 0 equals $1, E_{\max }$ is the maximum genotoxicity level, $c_{50}$ is the dose resulting in $50 \%$ of the maximum genotoxicity, $n$ is the Hill coefficient defining the shape of the dose-response curve and $c$ is the PAH concentration. When $n=1$, this model assumes the form of the familiar Michaelis-Menten equation.

At low doses, the Hill function simplifies into:

$E=1+a c^{n}$ with $a=\frac{E_{\max }-1}{c_{50}^{n}}$.

With a common value for $n$ for different compounds, it becomes straightforward to define toxicity equivalent factors at low levels as the $n$-root of the ratios of $a$ values.

We fitted the data obtained with the different PAHs and the two cell lines. Fit was performed using the weighted least squares method, the weights being the inverse of the variances for each concentration to correct for heteroscedasticity. We coded a program in $\mathrm{R}$ (Team, 2008). We fitted the data with distinct values for $E_{\max }, c_{50}$, and $n$ values for each PAH (complete model) and compared the quality of the fit with that of another model considering identical values for $n$ for all PAHs (reduced model). Comparison was performed through an F test analogous to the one used in nested models:

$\frac{\left(S S E_{r}-S S E_{c}\right) / p}{S S E_{c} /(N-k-p-1)}$

with $N$ the number of observations, $k$ the number of parameters in the reduced model, $p$ the difference in number of parameters between complete and reduced model, SSE the sums of the squared errors. Under the null hypothesis, this statistic has an F-distribution with $p$ and $N-(k+p+1)$ degrees of freedom.

\section{Results}

Genotoxic data in human cell lines

A new sensitive genotoxic assay based on histone H2AX phosphorylation detection (Audebert et al., 2010; Audebert et al., 2011) was used to determine the genotoxicity of 13 different PAHs on HepG2 cell line. All PAHs were analyzed for cytotoxicity and genotoxicity after $24 \mathrm{~h}$ treatment at different concentrations covering a four order of magnitude range (Fig. 1). Only non-cytotoxic concentrations (cell viability $>80 \%$ ) were analyzed for genotoxicity (data not shown). Three compounds (BghiP, Fla and Pyr) were found to be non genotoxic. A clear genotoxic dose-response effect was observed for the other PAHs. BaA, BcF, Chr and IP exhibited a genotoxic effect at concentrations $10^{-6} \mathrm{M}$ and upwards. BbF, BkF, DBahA and BaP were genotoxic at concentrations $10^{-7} \mathrm{M}$ and upwards. The two most genotoxic tested compound on this cell line were DMBA and DBalP, with a genotoxic potential at concentrations $10^{-8} \mathrm{M}$ and upwards (Fig. 1).
The same compounds were tested on LS-174T intestinal human cell line, which have been shown to be more appropriate than wellknown Caco-2 cells for the H2AX genotoxic assay (Audebert et al., 2010; Audebert et al., 2011). LS-174T cells were on average ten times more sensitive than HepG2 cells towards PAHs regarding genotoxicity (Fig. 2). The analysis of $\gamma$-H2AX dose-response data for the 9 different genotoxic PAHs on the two cell lines indicated a significant genotoxic signal at concentration 10 fold lower on the LS-174T cells compared to the HepG2 cells (See Figs. 1 and 2). On LS-174T cell line, two compounds, Fla and Pyr, did not induce genotoxicity. A dose-response genotoxic effect was observed for other investigated PAHs, starting from $10^{-6} \mathrm{M}$ for BghiP and IP, from $10^{-7} \mathrm{M}$ for BaA, $\mathrm{BbF}, \mathrm{BcF}, \mathrm{BkF}$, and $\mathrm{Chr}$, and from $10^{-8} \mathrm{M}$ for DBahA, DMBA, and $\mathrm{BaP}$; the most genotoxic tested compound on LS-174T cells was DBalP, with a genotoxic potential at concentrations $10^{-9} \mathrm{M}$ and upwards (Fig. 2).

\section{Toxicological equivalent factor based on dose-response modeling}

Estimates of the parameters are presented in Tables 1 and 2 together with a calculation of loss of explained variance when using a common shape value. For BaP and DBalP, it was not possible to identify $E_{\max }$ and $C_{50}$ for any of the two cell lines and we consequently used directly the simplified Hill function with $a$ and $n$. For HepG2 cells exposed to IP and BghiP, it was not possible to estimate the parameters due to high variability and low effects.

For HepG2 cells, the fits for BcF and DBahA were substantially impacted by the choice of a common value for $n$. For the other six compounds the $p$-value for the F-test was 0.29 , which confirms that we could use a common $n$ value for them. This common value was estimated at 0.98 , which suggests a quasi-linearity in the dose-response at low doses.

For LS-174T cell line, as for HepG2 cells, the fits for BcF, DBahA and BaP were substantially impacted by the choice of a common value for $n$. Once BcF and DBahA removed, the use of a common value was acceptable ( $p$-value of 0.19 ).

The statistical analysis thus indicates a significant difference in shape for two compounds, BcF and DBahA, whatever the cell line tested. For $\mathrm{BcF}$, estimated values for $n$ are either higher or lower than the common value, whereas for DBahA, it is always below.

The estimated Genotoxic Equivalent Factor (GEF) values were very similar between cell lines. They were all within a factor of 3 , the main difference having been found for $\mathrm{BkF}$ (with a factor of 2.6). Our study consequently provides a good basis for GEF calculation, as shown in Table 3.

\section{Discussion}

\section{Genotoxicity of PAHs in human cell lines}

A detailed analysis of the genotoxicity of 13 different PAHs on two human cell lines was performed in this study. Intestinal LS-174T cells were on average ten times more sensitive than hepatoma HepG2 cells towards PAHs regarding genotoxicity. PAHs are genotoxic after metabolization by CYP or Aldo-Keto Reductases (Xue and Warshawsky, 2005). The genotoxic sensitivity difference between the two cell lines tested could be explained by the difference in CYP expression and induction (Li et al., 1998; Iwanari et al., 2002). Iwanari and coworkers found that in LS180 cells (parent cells from which LS-174T are derived), CYP1A1, 1A2, and 1B1, the main CYPs involved in PAHs metabolism, are expressed at a higher level than on HepG2 cells. This observation at basal levels was also confirmed after induction by different PAHs (Iwanari et al., 2002).

In our study, Fla and Pyr were not genotoxic towards the two human cell lines tested. These data are in agreement with other studies indicating that neither Fla nor Pyr was mutagenic or genotoxic 


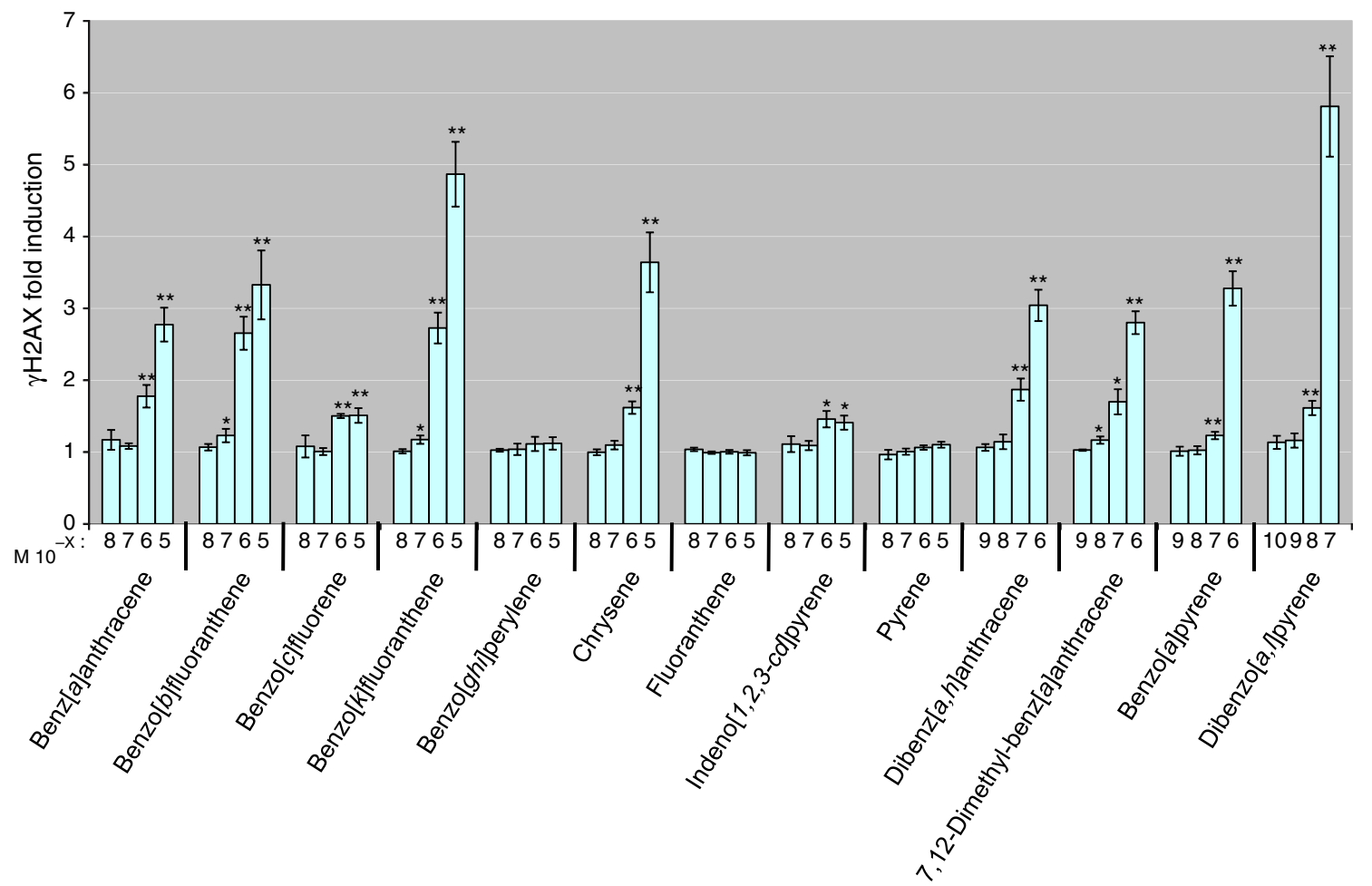

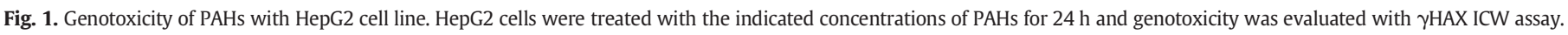

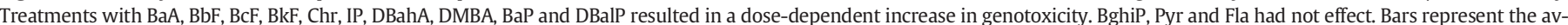
erage of at least four independent experiments with SEM. Statistically significant increase in H2AX phosphorylation compared with DMSO control; *, $p<0.05$; **, $p<0.01$.

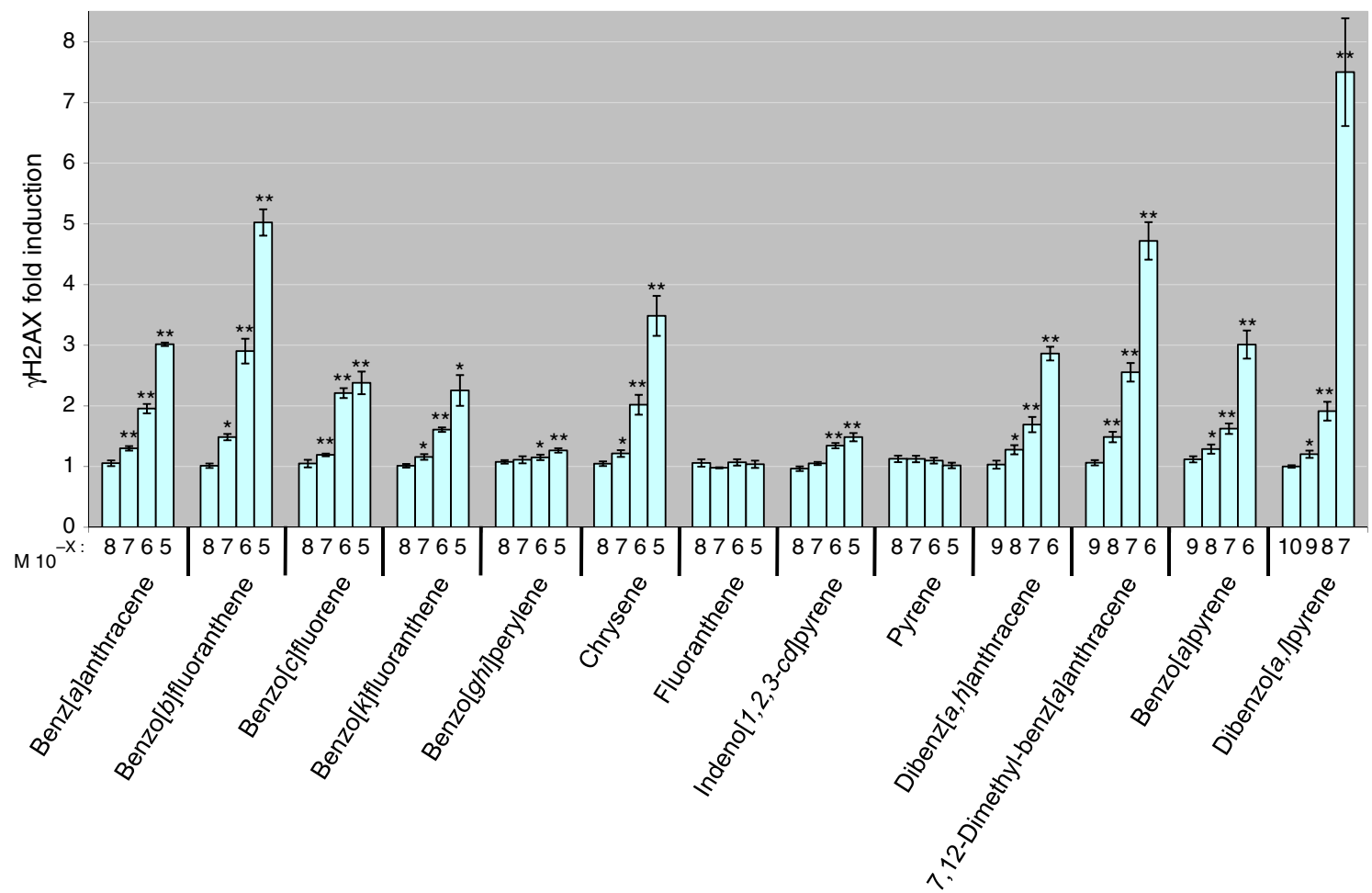

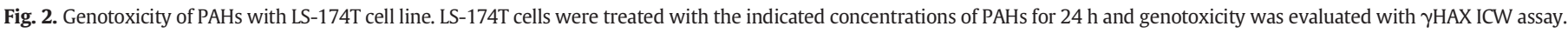

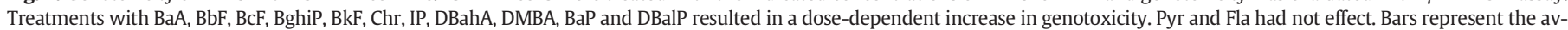
erage of at least four independent experiments with SEM. Statistically significant increase in H2AX phosphorylation compared with DMSO control; ${ }^{*}, p<0.05$; **, $p<0.01$. 
Table 1

Parameters estimated for HepG2 cells exposed to PAHs. L: the percentage of loss of explained variance compared to the residual variance using the complete model.

\begin{tabular}{|c|c|c|c|c|c|c|}
\hline \multirow[t]{2}{*}{ Compound } & \multicolumn{3}{|c|}{ Reduced model } & \multirow{2}{*}{$\begin{array}{l}\begin{array}{l}\text { Complete } \\
\text { model }\end{array} \\
n\end{array}$} & \multirow{2}{*}{$\begin{array}{l}\text { Loss of explained } \\
\text { variance (\%) } \\
\mathrm{L}\end{array}$} & \multirow{2}{*}{$\begin{array}{l}\text { Genotoxicity } \\
\text { Equivalent Factor } \\
\text { GEF }\end{array}$} \\
\hline & $a$ & $c_{50}$ & $n$ & & & \\
\hline $\mathrm{BaA}$ & 1.05 & 2.12 & 0.98 & 1.15 & 2.02 & 0.45 \\
\hline $\mathrm{BaP}$ & 2.28 & 0.98 & 0.99 & 0.02 & 1.00 & \\
\hline $\mathrm{BbF}$ & 3.29 & 0.83 & 0.98 & 0.18 & 2.39 & 1.46 \\
\hline $\mathrm{BcF}$ & 1.43 & 0.48 & 0.98 & 3.65 & 37.13 & 0.62 \\
\hline $\mathrm{BkF}$ & 2.27 & 2.17 & 0.98 & 1.21 & 10.45 & 1.00 \\
\hline Chr & 0.73 & 5.95 & 0.98 & 0.89 & 0.47 & 0.32 \\
\hline DBahA & 8.26 & 0.40 & 0.98 & 0.56 & 26.50 & 3.72 \\
\hline DMBA & 15.38 & 0.12 & 0.98 & 0.76 & 15.58 & 7.02 \\
\hline DBalP & 45.9 & 0 & 0.98 & 0.98 & 0 & 21.2 \\
\hline
\end{tabular}

(Vaca et al., 1992, Durant et al. 1996; Sjogren et al. 1996). Although the carcinogenic potential of Fla is considered as equivocal (Wang and Busby, 1993; Wang et al., 1995; Stocker et al., 1996), both Pyr and Fla were classified as non-carcinogenic (IARC, 2010).

Only LS-174T cells detected genotoxicity of BghiP, which was demonstrated to be mutagenic in human cells (Durant et al., 1996), and to be carcinogenic and able to form DNA adducts in vivo (Hughes and Phillips, 1993).

Although a dose-response genotoxic effect was observed for the others PAHs tested on LS-174T and HepG2 cells, BbF and BkF display different genotoxic potentials on the two cell lines. The genotoxicity of $\mathrm{BbF}$ and $\mathrm{BkF}$ on HepG2 cells was of the same order of magnitude whereas on LS-174T cells BbF is a much more potent genotoxic compound than BkF (Figs. 1 and 2). The potency of BbF was also higher than BkF in terms of carcinogenicity (Wynder and Hoffmann, 1959), mutagenicity (Durant et al., 1996) and CYP induction (Louiz et al., 2008). Recently, RPFs of these compounds were revaluated, resulting in a value of 0.8 for BbF and 0.03 for BkF (US-EPA, 2010).

To our knowledge, this is the first study investigating the genotoxicity of BcF on human cell lines. BcF was found to be nonmutagenic in the Ames assay (Lavoie et al., 1981) but was able to form DNA adducts in vivo (Koganti et al., 2000; Weyand et al., 2002; Cizmas et al., 2004). In addition, it is considered as a more potent carcinogenic hydrocarbon than BaP in rodents (Weyand et al., 2004). In our study, both HepG2 and LS-174T cell lines gave positive genotoxic results with this compound, although the response observed with LS-174T cells was substantially higher than for HepG2 (Figs. 1 and 2). Modeling the genotoxic potency of BcF resulted in a proposed value of 0.5 compared to BaP. However, the estimated slope $(n)$ in the complete dose-response model is strongly different

Table 2

Parameters estimated for LS-174T cells exposed to PAHs. L: the percentage of loss of explained variance compared to the residual variance using the complete model.

\begin{tabular}{|c|c|c|c|c|c|c|}
\hline \multirow[t]{2}{*}{ Compound } & \multicolumn{3}{|c|}{ Reduced model } & \multirow{2}{*}{$\begin{array}{l}\text { Complete } \\
\text { model } \\
n\end{array}$} & \multirow{2}{*}{$\begin{array}{l}\text { Loss of explained } \\
\text { variance (\%) } \\
\mathrm{L}\end{array}$} & \multirow{2}{*}{$\begin{array}{l}\text { Genotoxicity } \\
\text { Equivalent Factor } \\
\text { GEF }\end{array}$} \\
\hline & $a$ & $c_{50}$ & $n$ & & & \\
\hline $\mathrm{BaA}$ & 1.78 & 1.54 & 0.78 & 0.64 & 11.55 & 0.80 \\
\hline $\mathrm{BaP}$ & 2.12 & 0.78 & 0.48 & 42.38 & 1.00 & \\
\hline $\mathrm{BbF}$ & 3.04 & 1.97 & 0.78 & 0.85 & 5.46 & 1.59 \\
\hline $\mathrm{BcF}$ & 1.63 & 1.39 & 0.78 & 1.60 & 51.87 & 0.72 \\
\hline BghiP & 0.24 & 0.99 & 0.78 & 0.23 & 12.63 & 0.10 \\
\hline $\mathrm{BkF}$ & 1.00 & 1.78 & 0.78 & 0.79 & 11.20 & 0.38 \\
\hline Chr & 1.43 & 3.13 & 0.78 & 0.77 & 12.08 & 0.61 \\
\hline IP & 0.52 & 0.70 & 0.78 & 0.98 & 8.2 & 0.2 \\
\hline DBahA & 3.71 & 1.18 & 0.78 & 0.50 & 28.07 & 2.05 \\
\hline DMBA & 15.51 & 0.22 & 0.78 & 0.68 & 5.34 & 12.87 \\
\hline DBalP & 39 & 0.78 & 0.85 & 2.5 & 35.7 & \\
\hline
\end{tabular}

Table 3

Proposed Genotoxicity Equivalent Factors (GEF) for polycyclic aromatic hydrocarbons.

\begin{tabular}{llll}
\hline Compound & Genotoxicity Equivalent Factor & & Relative potency factor \\
\cline { 2 - 2 } & GEF & & RPF \\
\hline BaA & 0.5 & 0.2 \\
BaP & 1 & 1 \\
BbF & 1.5 & 0.8 \\
BcF & 0.5 & 20 \\
BghiP & 0.1 & 0.009 \\
BkF & 1 & 0.03 \\
Chr & 0.3 & 0.1 \\
IP & 0.2 & 0.07 \\
DBahA & 2 & 10 \\
DMBA & 10 & n.d. \\
DBalP & 25 & 30 \\
Fla & 0.001 & 0.08 \\
Pyr & 0.001 & 0 \\
\hline
\end{tabular}

n.d. not determined.

a From US-EPA (2010).

from the estimated common value $(n)$ obtained with the reduced model. This observation suggests the hypothesis that the BcF could have a mode of action and metabolism different from other PAHs such as BaP.

It was established recently by different teams that the $\gamma$-H2AX assay was more sensitive than the comet test, notably in vivo (Trouiller et al., 2009) but also in vitro (Ismail et al., 2007; Watters et al., 2009; Leopardi et al., 2010). Moreover, this assay was found to be more sensitive than the comet assay when we compare our results regarding PAHs genotoxicity with published data on the same cell line (Plazar et al., 2007; Winter et al., 2008; Tarantini et al., 2009). Concerning the comparison of the $\gamma$-H2AX assay with the micronucleus test, it is now well established that the micronucleus formation correlates well with H2AX phosphorylation (Medvedeva et al., 2007; Terradas et al., 2009; Yoshikawa et al., 2009).

In conclusion, the $\gamma$-H2AX genotoxic assay combined with the In Cell Western technique allows a sensitive and rapid determination of cell viability concomitantly to genotoxicity, making this approach compatible with a high throughput screening when used in 96-well plates. This test can be performed on a wide set of human cell lines, which are considered as more reliable to human toxicity than biological systems such as bacterial mutagenicity tests or rodent cell tests.

\section{Genotoxic Equivalent Factor determination}

Several approaches are available for the determination of RPF or TEF for PAHs. Most of the published TEF rely on similar bioassay data and modeling methods, and the resulting TEF values are fairly comparable for most PAHs across studies (Nisbet and LaGoy, 1992; Sjogren et al., 1996). However, the data were generally issued from rodent carcinogenic studies with high doses of PAHs, and difference of susceptibility to PAHs may exist between species (Grisham, 1997). In the second part of this study we described a new approach to determine the GEF for 13 PAHs based on modeling the data we obtained with human cancer cells. To establish the GEF, we used a Hill model for dose-response modeling for HAPs. In contrast to other existing approaches (US-EPA, 2010), our methodology was not based on linear extrapolation but on the simultaneous fit of all PAH data with a common shape for dose-response. This permitted both to identify compounds with a specific dose-response and to propose valid GEF values for the whole low dose region. Our GEF are, for most tested compounds, higher than usually utilized TEF, notably once based on AMES data (Nisbet and LaGoy, 1992; Sjogren et al., 1996). This difference could be explained by the fact that we used genotoxic data from human cancer cells, low doses of PAHs (nanomolar range), a global genotoxic measure and a new modeling method. 
Underestimated TEF values could partly explain the disparity between theoretical and practical genotoxic data for mixtures of PAHs (Rodriguez et al., 1997; Baird et al., 2005) and could result in an underestimation of risk. Nonetheless, our GEF values are similar to other published TEFs (Durant et al., 1996; Louiz et al., 2008; USEPA, 2010) (Table 3), in particular for highly genotoxic and carcinogenic compounds DBahA (Nisbet and LaGoy, 1992), DMBA (Collins et al., 1998), and DBalP (Wynder and Hoffmann, 1961). For BcF, BghiP and IP, for which a limited number of available carcinogenesis data exist, a more important difference is observed between our equivalent factors and those reported by the US EPA (US-EPA, 2010). Nonetheless, for the three compounds the relative confidence rating suggested by US EPA study was medium or low, due to the weakness of the database used (US-EPA, 2010).

To conclude, we propose Genotoxic Equivalent Factors (GEF) for PAHs. These GEFs were obtained with human cells using a new in vitro genotoxic assay. Modeling dose-response relationships highlighted discrepancies between PAHs and allowed us to estimate the ratios of concentrations that lead to the same dose-response curve at low exposure, between each PAH and BaP. These GEFs, which are not based on methodological approaches considered irrelevant for foodborne contaminants (e.g. mouse carcinogenicity studies using skin application) are applicable to the risk assessment of mixtures of genotoxic PAHs such as the 8 indicators suggested by EFSA as representative of the occurrence of PAHs in food.

As compared to currently available methods based on TEFs and used to assess the risk of PAHs for human health, our approach present several advantages, among which (1) the reliance on cancerrelated endpoint bioassays, (2) the consistency of testing PAHs in human cell lines derived from potential target tissues (i.e. hepatic and intestinal tissues), compared to bacteria or to other mammalian cells (although some uncertainties exist regarding the predictive value of genotoxicity data in human cell lines for the tumor formation process in humans), (3) the asset of cell types with intrinsic metabolic capacities, avoiding the use of S9 mix which can result in an overor under-estimation of the genotoxic response, (4) the sensitivity of the H2AX assay allowing dose-response studies including low dose testing, a potency comparison. In addition, the current mathematical modeling of dose-response data represents a substantial improvement upon the previous linear extrapolation (US-EPA, 2010).

\section{Conflict of interest statement}

The authors declare that there are no conflicts of interest.

\section{Acknowledgments}

The authors would like to thank Dr. C. Tebby for reviewing this manuscript. This research was funded by the ANSES PNREST program and the "Institut National Contre le cancer" (Contract no. 2010-371)

\section{References}

Audebert, M., Dolo, L, Perdu, E. Cravedi, J.P. Zalko, D., 2011. Use of the gammaH2AX assay for assessing the genotoxicity of bisphenol $\mathrm{A}$ and bisphenol $\mathrm{F}$ in human cell lines. Arch. Toxicol. 85, 1463-1473.

Audebert, M., Riu, A., Jacques, C., Hillenweck, A., Jamin, E.L., Zalko, D., Cravedi, J.P., 2010 Use of the gammaH2AX assay for assessing the genotoxicity of polycyclic aromatic hydrocarbons in human cell lines. Toxicol. Lett. 199, 182-192.

Baird, W.M., Hooven, L.A., Mahadevan, B., 2005. Carcinogenic polycyclic aromatic hydrocarbon-DNA adducts and mechanism of action. Environ. Mol. Mutagen. 45, 106-114.

Bostrom, C.E., Gerde, P., Hanberg, A., Jernstrom, B., Johansson, C., Kyrklund, T., Rannug, A., Tornqvist, M. Victorin, K. Westerholm, R, 2002. Cancer risk assessment, indicators, and guidelines for polycyclic aromatic hydrocarbons in the ambient air. Environ. Health Perspect. 110 (Suppl 3), 451-488.

Cizmas, L., Zhou, G.D., Safe, S.H., McDonald, T.J., Zhu, L., Donnelly, K.C., 2004. Comparative in vitro and in vivo genotoxicities of ${ }^{7} \mathrm{H}$-benzo[c]fluorene, manufactured gas plant residue (MGP), and MGP fractions. Environ. Mol. Mutagen. 43, 159-168.
Collins, J.F., Brown, J.P., Alexeeff, G.V., Salmon, A.G., 1998. Potency equivalency factors for some polycyclic aromatic hydrocarbons and polycyclic aromatic hydrocarbon derivatives. Regul. Toxicol. Pharmacol. 28, 45-54.

European Commission, 2002. Opinion of the Scientific Committee on Food on the Risks to Human Health of Polycyclic Aromatic Hydrocarbons in food. http://ec.europa. eu/food/fs/sc/scf/out153_en.pdf.

Durant, J.L., Busby Jr., W.F., Lafleur, A.L., Penman, B.W., Crespi, C.L., 1996. Human cell mutagenicity of oxygenated, nitrated and unsubstituted polycyclic aromatic hydrocarbons associated with urban aerosols. Mutat. Res. 371, 123-157.

EFSA, 2008. Polycyclic aromatic hydrocarbons in food. The EFSA journal 724, 1-114.

FAO/WHO, 2005. Joint FAO/WHO Expert Committee on Food Additives (JECFA). Sixtyfourth meeting, Rome, 8-17 February 2005. Summary and Conclusions. http:// www.who.int/ipcs/food/jecfa/summaries/summary_report_64_final.pdf.

Graillot, V., Takakura, N., Le Hegarat, L., Fessard, V., Audebert, M., Cravedi, J.P., 2012. Genotoxicity of pesticide mixtures present in the diet of the French population. Environ. Mol. Mutagen.. doi:10.1002/em.21676

Grisham, J.W., 1997. Interspecies comparison of liver carcinogenesis: implications for cancer risk assessment. Carcinogenesis 18, 59-81.

Hughes, N.C., Phillips, D.H., 1993. ${ }^{32}$ P-postlabelling analysis of the covalent binding of benzo[ghi]perylene to DNA in vivo and in vitro. Carcinogenesis 14, 127-133.

IARC, 2010. Some non-heterocyclic polycyclic aromatic hydrocarbons and some related exposures. IARC Monographs on the Evaluation of Carcinogenic Risks to Humans, V92.

Ismail, I.H., Wadhra, T.I., Hammarsten, O., 2007. An optimized method for detecting gamma-H2AX in blood cells reveals a significant interindividual variation in the gamma-H2AX response among humans. Nucleic Acids Res. 35, e36.

Iwanari, M., Nakajima, M., Kizu, R., Hayakawa, K., Yokoi, T., 2002. Induction of CYP1A1, CYP1A2, and CYP1B1 mRNAs by nitropolycyclic aromatic hydrocarbons in various human tissue-derived cells: chemical-, cytochrome P450 isoform-, and cellspecific differences. Arch. Toxicol. 76, 287-298.

Koganti, A., Singh, R., Rozett, K., Modi, N., Goldstein, L.S., Roy, T.A., Zhang, F.J., Harvey, R.G., Weyand, E.H., 2000. 7H-benzo[c]fluorene: a major DNA adduct-forming component of coal tar. Carcinogenesis 21, 1601-1609.

Lavoie, E.J., Tulley, L., Bedenko, V., Hoffmann, D., 1981. Mutagenicity of methylated fluorenes and benzofluorenes. Mutat. Res. 91, 167-176.

Leopardi, P., Cordelli, E., Villani, P., Cremona, T.P., Conti, L., De Luca, G., Crebelli, R., 2010. Assessment of in vivo genotoxicity of the rodent carcinogen furan: evaluation of DNA damage and induction of micronuclei in mouse splenocytes. Mutagenesis $25,57-62$

Li, W., Harper, P.A., Tang, B.K., Okey, A.B., 1998. Regulation of cytochrome P450 enzymes by aryl hydrocarbon receptor in human cells: CYP1A2 expression in the LS180 colon carcinoma cell line after treatment with 2,3,7,8-tetrachlorodibenzop-dioxin or 3-methylcholanthrene. Biochem. Pharmacol. 56, 599-612.

Louiz, I., Kinani, S., Gouze, M.E., Ben-Attia, M., Menif, D., Bouchonnet, S., Porcher, J.M. Ben-Hassine, O.K., Ait-Aissa, S., 2008. Monitoring of dioxin-like, estrogenic and anti-androgenic activities in sediments of the Bizerta lagoon (Tunisia) by means of in vitro cell-based bioassays: contribution of low concentrations of polynuclear aromatic hydrocarbons (PAHs). Sci. Total Environ. 402, 318-329.

Lutz, W.K., 1991. Dose-response relationship for chemical carcinogenesis by genotoxic agents. Soz. Praventivmed. 36, 243-248.

Medvedeva, N.G., Panyutin, I.V., Panyutin, I.G., Neumann, R.D., 2007. Phosphorylation of histone H2AX in radiation-induced micronuclei. Radiat. Res. 168, 493-498.

Nisbet, I.C., LaGoy, P.K., 1992. Toxic equivalency factors (TEFs) for polycyclic aromatic hydrocarbons (PAHs). Regul. Toxicol. Pharmacol. 16, 290-300.

O'Brien, P.J., Irwin, W., Diaz, D., Howard-Cofield, E., Krejsa, C.M., Slaughter, M.R., Gao, B., Kaludercic, N., Angeline, A., Bernardi, P., Brain, P., Hougham, C., 2006. High concordance of drug-induced human hepatotoxicity with in vitro cytotoxicity measured in a novel cell-based model using high content screening. Arch. Toxicol. 80, 580-604.

Plazar, J., Hreljac, I., Pirih, P., Filipic, M., Groothuis, G.M., 2007. Detection of xenobioticinduced DNA damage by the comet assay applied to human and rat precision-cut liver slices. Toxicol. In Vitro 21, 1134-1142.

Rodriguez, L.V., Dunsford, H.A., Steinberg M., Chaloupka, K.K., Zhu, L., Safe, S., Womack, J.E., Goldstein, L.S., 1997. Carcinogenicity of benzo[a]pyrene and manufactured gas plant residues in infant mice. Carcinogenesis 18, 127-135.

Safe, S.H., 1998. Hazard and risk assessment of chemical mixtures using the toxic equivalency factor approach. Environ. Health Perspect. 106 (Suppl 4), 1051-1058.

Sjogren, M., Ehrenberg, L., Rannug, U., 1996. Relevance of different biological assays in assessing initiating and promoting properties of polycyclic aromatic hydrocarbons with respect to carcinogenic potency. Mutat. Res. 358, 97-112.

Stocker, K.J., Howard, W.R., Statham, J., Proudlock, R.J., 1996. Assessment of the potential in vivo genotoxicity of fluoranthene. Mutagenesis 11, 493-496.

Tarantini, A, Maitre, A., Lefebvre, E., Marques, M., Marie, C., Ravanat, J.L, Douki, T. 2009. Relative contribution of DNA strand breaks and DNA adducts to the genotoxicity of benzo[a]pyrene as a pure compound and in complex mixtures. Mutat. Res. 671, 67-75.

Team, R.D.C., 2008. R: a language and environment for statistical computing. ISBN 3900051-07-0, URL R Foundation for Statistical Computing, Vienna, Austriahttp:// www.R-project.org.

Terradas, M., Martin, M., Tusell, L. Genesca, A., 2009. DNA lesions sequestered in micronuclei induce a local defective-damage response. DNA Repair (Amst) 8, 1225-1234.

Trouiller, B., Reliene, R., Westbrook, A., Solaimani, P., Schiestl, R.H., 2009. Titanium dioxide nanoparticles induce DNA damage and genetic instability in vivo in mice. Cancer Res. 69, 8784-8789.

US-EPA, 2010. Development of a Relative Potency Factor (RPF) Approach for Polycyclic Aromatic Hydrocarbon (PAH) Mixtures (External Review Draft). U.S. Environmental Protection Agency, Washington, DC. EPA/635/R-08/012A. 
Vaca, C., Tornqvist, M., Rannug, U., Lindahl-Kiessling, K., Ahnstrom, G., Ehrenberg, L., 1992. On the bioactivation and genotoxic action of fluoranthene. Arch. Toxicol. 66, 538-545.

Van den Berg, M., Birnbaum, L., Bosveld, A.T., Brunstrom, B., Cook, P., Feeley, M., Giesy, J.P., Hanberg, A., Hasegawa, R., Kennedy, S.W., Kubiak, T., Larsen, J.C., van Leeuwen, F.X., Liem, A.K., Nolt, C., Peterson, R.E., Poellinger, L., Safe, S., Schrenk, D., Tillitt, D., Tysklind, M., Younes, M., Waern, F., Zacharewski, T., 1998. Toxic equivalency factors (TEFs) for PCBs, PCDDs, PCDFs for humans and wildlife. Environ. Health Perspect. 106, 775-792.

Walker, N.J., Yang, J.H., 2005. Complexities in understanding the nature of the dose-response for dioxins and related compounds. Dose Response 3, 267-272.

Wang, J.S., Busby Jr., W.F., 1993. Induction of lung and liver tumors by fluoranthene in a preweanling CD-1 mouse bioassay. Carcinogenesis 14, 1871-1874.

Wang, J.S., Busby Jr., W.F., Wogan, G.N., 1995. Formation and persistence of DNA adducts in organs of CD-1 mice treated with a tumorigenic dose of fluoranthene. Carcinogenesis 16, 2609-2616.

Watters, G.P., Smart, D.J., Harvey, J.S., Austin, C.A., 2009. H2AX phosphorylation as a genotoxicity endpoint. Mutat. Res. 679, 50-58.

Weyand, E.H., Modi, N., Parimoo, B., Mauro, D.M., Craig, D.R., 2002. Evaluation of PAH: DNA adduct formation in rats fed coal tar-contamined diets. Polycyclic Aromat. Compd. 22, 911-921.
Weyand, E.H., Parimoo, B., Reuhl, K.R., Goldstein, L.S., Wang, J.Q., Harvey, R.G., 2004 7H-benzo[c]fluorene: a potent systemic lung carcinogen. Polycyclic Aromat. Compd. $24,1-20$.

Winter, H.K., Ehrlich, V.A., Grusch, M., Lackner, A., Schulte-Hermann, R., Grasl-Kraupp, B., Mikulits, W., Knasmuller, S., 2008. Use of four new human-derived liver-cell lines for the detection of genotoxic compounds in the single-cell gel electrophoresis (SCGE) assay. Mutat. Res. 657, 133-139.

Wynder, E.L., Hoffmann, D., 1959. The carcinogenicity of benzofluoranthenes. Cancer 12, 1194-1199.

Wynder, E.L., Hoffmann, D., 1961. Carcinogenicity of dibenzo(a, l)pyrene. Nature 192 1092-1093.

Xue, W., Warshawsky, D., 2005. Metabolic activation of polycyclic and heterocyclic aromatic hydrocarbons and DNA damage: a review. Toxicol. Appl. Pharmacol. 206, 73-93.

Yoshikawa, T. Kashino, G., Ono, K. Watanabe, M., 2009. Phosphorylated H2AX foci in tumor cells have no correlation with their radiation sensitivities. J. Radiat. Res. (Tokyo) 50, 151-160.

Zhou, C., Li, Z., Diao, H., Yu, Y., Zhu, W., Dai, Y., Chen, F.F., Yang, J., 2006. DNA damage evaluated by gammaH2AX foci formation by a selective group of chemical/physical stressors. Mutat. Res. 604, 8-18. 